\title{
Study on Growth Performance of Strategic New Industries
}

\author{
Rui $\mathrm{Li}^{1, \mathrm{a}^{*}}$, Liwen Sun ${ }^{1, \mathrm{~b}}$ and Jingwei $\mathrm{Lv}^{1, \mathrm{c}}$ \\ ${ }^{1}$ School of Economics and Management, Hebei University of Technology, Tianjin, P.R.China

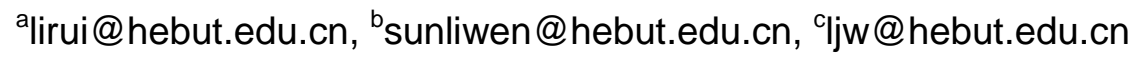

Keywords: Strategic new Industry; Growth performance; Influential factors; Questionnaire analysis

\begin{abstract}
To speed up the industry transformation and upgrading, keep the sustainable development of the national or regional economic development in a long term, on the basis of reviewing relative references, this article introduces a concept model of the strategic new industries, and measure their growth performance with five types of questions, which include growth capability, level of maturity, growth scale, level of technological development, and stability of market structure. Meanwhile, the results of questionnaire analysis and valid reliability analysis verify the concept model. In the end, the empirical analysis about the growth factors of the strategic new industries is made through a regression model. At the level of 5\%, the regression coefficient is notable, which meant the model fit well. This variable equals to $R^{2}$ as 0.626 , which means the predicable variables chosen by this study can explain the $62.6 \%$ variation of the criterion variable in the strategic new industrial "growth performance". The results indicates that the development of strategic new enterprises and industries still need to be achieved by improving technological innovation ability, which is an indirect reflection of our domestic strategic new industrial development.
\end{abstract}

\section{Introduction}

Strategic new industry refers to the growing new industry which represents the direction of technological development of a country or a region, and on the basis of innovation of technology and business model, becomes the dominating power of the future economy of a country. ${ }^{[1]}$ From the point of performance characteristic, the outward performance of growth is a process of a life cycle, in which the scale grows from small to great, structure from simple to complex, competitiveness from weak to strong. The inward performance demonstrates changes in three aspects: the scale, technology and organization of the industry. From the view of research, industry growth focuses on the medium measure, emphasize the strength and maturity of the single industry, and the variation of scale, technology and organization during its growing process. ${ }^{[2]}$

In the "Decision on Speeding up Cultivating and Developing Strategic New Industry" in 2010, the State Council made it clear that as an important leading force to the development of economy and society, strategic new industries are main approaches to rehabilitate the economy in the "post-crisis era" and important breakthrough points of the regional economy, which are highly related to the international competitiveness of the national economy. ${ }^{[3-4]}$ Furthermore, the scholars of China and overseas show their strong interests in the development of strategic new industry. Girma et al. (2008) ${ }^{[5]}$, Jefferson et al. $(2006)^{[6]}$, Tsai and $\mathrm{Wu}(2009)^{[7]}$, Macher et al. (2007) ${ }^{[9]}$ made studies on new technology industry from the aspects of financing, technology innovation R\&D and market expanding. Comparatively, Goerg and Strobl (2007) ${ }^{[10]}$ and Yingyi T. (2009) [11] took national strategic industries as their study objects. Chinese scholars, such as LIU Zhiyang(2010) ${ }^{[12]}$, GU Haifeng (2011) ${ }^{[13]}$, HE Zhengchu $(2011)^{[3]}$, and Lin Pingfan(2010 $)^{[14]}$ mainly discussed the contents, growing conditions, cultivation policies and evaluation standards of the 
Strategic New Industries. This article will take HeBei Province as an example to analyze the influential factors on the strategic new Industries, so that to help to solve the crucial problem about how to keep a sustainable and healthy growth in the development of these industries.

\section{Index System Foundation of Strategic New Industries}

Options for the index system. Yingyi T. (2009) ${ }^{[11]}$ take innovation, financing and market as the three important factors which influence the growth of strategic new industry in the developing countries, and set up a three-stage model for the growth of the new industry. Shih-Chang Hung (2006) ${ }^{[16]}$ take Taiwan as an example to bring the influence of government to the new technologies into consideration. He Zhengchu (2010) evaluate the choosing of strategic new industry with five options: government support, resource environment, market, technology research and development, strategic newness. ${ }^{[4]}$ Lin Ping-fan, Liu Cheng (2010) argues that the growth foundation and guarantee of strategic new industry includes industrial base, technological drive, financial support, personnel propping and investment mechanism. ${ }^{[14]}$ Zhang Liangqiao et. al. (2010) think that the choice of index system for the strategic new industry should follow three principles: scientificity, completeness and principle factors. And the property of the evaluation index system should include policy orientation, economic benefits, innovative capacity, and development potentiality. ${ }^{[15]}$ Fang Rulin (2011) argued that technology innovation is the main drive to the strategic new industry, and the market competitive mechanism and the government industrial cultivation mode has enormous influence upon strategic new industry. ${ }^{[17]}$

Index Setting. According to the conceptual Mode of strategic new industry growth, this article divided the influential factors into internal dimension and external dimension, and set 4 indexes to interpret the influential factors, including Technological innovation $\left(X_{1}\right)$, Capital financing $\left(X_{2}\right)$, Human resources $\left(X_{3}\right)$, Market necessity $\left(X_{4}\right)$ and set the growth performance indexes with Growth strength $\left(Y_{1}\right)$ 、maturity level $\left(Y_{2}\right)$, growth scale $\left(Y_{3}\right)$, technology development level $\left(Y_{4}\right)$.

Data Acquisition. 200 questionnaires were issued, and 157 effective ones have been collected back. From the collected questionnaires, the investigating rates are higher in four industries, new information technology, high-end equipment fabrication, new material, energy efficiency and environmental protection, which were $23.86 \%, 10.23 \%, 9.09 \%$, and $8.52 \%$. From the view of unit character, enterprises were $56.78 \%$, local governments were $34.09 \%$, research institutions were $6.25 \%$, and universities were $2.88 \%$. $88.64 \%$ of the respondents have bachelor's degree or higher. The analysis to the return questionnaires told a fact that $\mathrm{T}$ verifications according to industries were all unobvious, that because the constraints and the newness, strategic new industries in Hebei province were still at a beginning stage with no presentation of development rules in the industrial circle.

Reliability and Validity Analysis. According to the above criterion, and after using SPSS $17.0^{[18]}$ to analyze the effective questionnaire, "purchasing patent" in the internal "technological innovation" factors, "own funds" in the "capital financing" factors should be deleted, which meant comparing to the other technological obtaining ways, purchasing patent was less in common. It is the same with self-own found to the other financing channels. These items were different to the expecting testing behavioral or psychological characteristics. Under the same consideration, the behavioral or psychological characteristics presented by the "direct purchasing" in "macro-regulation and control", "domestic market" in "market necessity" were not the same with the expecting ones; these items should be deleted in the further analysis.

After deleting the above four items, the extracted square and loading cumulative variance rate from $\alpha$ Coefficient, common factor variance and the explained total factor of the project 
have been improved.

Regression Analysis. From the result, multiple correlation coefficients was 0.791 , the square which decided the multiple correlation coefficient was 0.626 , and the adjusted $R^{2}$ was 0.609 , the estimated standard error of the sum of squared errors of the regression model was 0.6256 . In the process of regression analysis, this study took the method of forcing variable, with only one regression model. This variable equals to $R^{2}$ as 0.626 , which means the predicable variables chosen by this study can explain the $62.6 \%$ variation of the criterion variable in the strategic new industrial "growth performance".

The Abstract of Variance Analysis on Regression Model showed that the value of $F$ was 35.646, and $p_{\text {for }}$ the significant test was 0.000 , which meant this regression model was significant at the level of $5 \%$ in explaining the overall variables.

From the coefficient and significant test of regression mode, it includes non-standard regression coefficient, standard regression coefficient, the value of $t$ in the regression coefficient of significant test, and the significant probability value. The bigger the absolute value of $\beta$ is, the more prominent the influence of the probability value to the criterion variable of strategic new industrial growth performance will be, which will leading to a more distinctive variation of the explained dependent variable. The non-standard regression formula can be seen as formula (1). $Y=-7.324 \mathrm{E}^{-17}-0.042 X_{1}+0.080 X_{2}+0.139 X_{3}+0.188 X_{4}$

The value of $\beta$ is usually used to predict the probable value of samples with the regression formula. Because non-standard regression coefficients include constant terms (intercept), it is impossible to compare the comparative significance of the probability variables. In the actual studies, the non-standard regression formula is usually transformed into a standard one. The result of this research about the non-standard intercept was $-7.324 \mathrm{E}^{-17}$, which could be ignored. The coefficients have no change after standardization; therefore a standard regression mode comes out as formula (2).

$$
Y=-0.042 X_{1}+0.080 X_{2}+0.139 X_{3}+0.188 X_{4}
$$

\section{Conclusion}

The standard variance showed that the standard regression coefficients of three independent variables were all positive, which meant their influence to strategic new industrial growth performance was positive-going. The cross correlation coefficients between the standard regression coefficient $\beta$ and former product-moment correlation coefficient were positive and the influence from these two coefficients to the criterion variable was all positive-going. At the same time, the values of $t$ in the regression coefficient significant test were all less than 0.05 , and at the level of $5 \%$, the regression coefficient is notable, which meant the model fit well. However, the negative figure of the standard regression coefficient of technological innovation variable ( $\left.X_{1}\right)$ shows that this variable's influence to strategic new industrial growth performance is negative-going, which is highly related to the low domestic technological innovation ability at this stage. The results indicated that the development of strategic new enterprises and industries still need to be achieved by improving technological innovation ability, which was an indirect reflection of our domestic strategic new industrial development.

\section{Acknowledgement}

This work was financially supported by the National Nature Science Fund Project( 71403078), the Humanities and Social Sciences Youth Fund of Ministry of Education ( 13YJC630086), Hebei 
Social Science Fund(HB15YJ097), Tianjin Social Science Planning Project(TJGL15-008). Tianjin Social Science Planning Project (TJYYHQ1403), Hebei Social Science Research Subject (2015040221).

\section{References}

[1] Wang Zheng. The growth mechanism and development strategies of Chinese strategic new industries. Innovation, 3 (2014):16-20.

[2] Xiang Jiying. Industrial growth and its periodical characteristics — based on the analysis on the "S" curve, Academic Forums. 5 (2007):83-87.

[3] Gui Huangbao. Analysis on growth drive mechanism of strategic new industries-Chinese domestic new energy automobile as an example. Scientific Management Research. 30(2012): 48-51.

[4] He Zheng-chu; Zhang Xun; Zhou Zhenhong. To choose and evaluate strategic new industries and an empirical analysis. Science of Science and Management of S. \& T. 31(2012): 62-67.

[5] Girma S., Gong,Y., Goerg,H.. Foreign direct investment, access to finance, and innovation activity in Chinese enterprises. The World Bank Economic Review, 22(2008):367-382.

[6] Jefferson G..H., Huamao, B., Xiaojing, G., Xiaoyun, Y.. R\&D performance in Chinese industry. Economics of Innovation and New Technology, 15 (2006): 345-366.

[7] Tsai, Y., Wu, C. Integrated production and the investment-uncertainty relationship. South African Journal of Economics. 77(2009):102-112.

[8] Brown,C,Linden,G.. Off shoring in the semiconductor industry: a historical perspective. Brookings Trade Forum. 2005, pp:279-322.

[9] Macher, J.T., Mowery, D.C., Di Minin, A. The non-globalization of innovation in the semiconductor industry. California Management Review, 50 (2007): 1-26.

[10]Goerg.H., Strobl,E.. The effect of R\&D subsidies on private R\&D. Economica, 74 (2007):215-234.

[11] Yingyi Tsai, Justin Yifu Lin, Lucia Kurekova. Innovative R\&D and optimal investment under uncertainty in high-tech industries: An implication for emerging economies, Research Policy, 38 (2009):1388-1395

[12]Liu, Zhiyang; Cheng, Haishi. Strategic new industrial cluster cultivation and network features. Reform. 5 (2010):36-42.

[13] Gu Haifeng. Evolutional condition and financial support of Chinese domestic strategic new industries. Securities Market Herald. 4 (2011):57-61.

[14]Lin, Pingfan; Liu, Cheng. The growth condition and cultivation solutions of strategic new industries of Guang Dong Province. Science and Technology Management Research. 20(2010): 67.

[15]Zhang, Liangqiao; He Zhengchu; Wu, Yan. Strategic new industries evaluation on the basis of grey correlation analysis-biomedicine as an example. Journal of Quantitative Economics. (9)2010:79-84. 
[16] Shih-Chang Hung, Yee-Yeen Chu. Stimulating new industries from emerging technologies: challenges for the public sector. Technovation, (26)2006: 104-110.

[17][17] Fang, Rulin; He, Furong; Bian, Ran. Study on the strategy and path of Chengdu's strategic new industries development. China Urban Economy. (8)2011: 384-386.

[18][18] Deng Weibin, Tang Xingyan, Hu Daquan, Zhou Yumin. SPSS Statistical Analysis Practical Guide, Publish House of Electronics Industry. Beijing: 2012, pp.230-250. 